\title{
Hidden Phenomena During Transient Reaction Trajectories in Liquid Metals Processing
}

\author{
STEPHEN SPOONER, ZUSHU LI, and SEETHARAMAN SRIDHAR
}

The transient trajectory taken for a system striving toward equilibration has consequences on the rate of processes and on the chemical and physical state of products in metallurgical processes. A case study approach to recent advancements in liquid steel processing is given. A combination of techniques and knowledge developed is given as a targeted showcase of the authors' contributions to the understanding of liquid metal droplet reactions and their contribution to the large-scale production processes within the steel industry. Examples relevant to novel ironmaking technologies, oxygen steelmaking, ladle metallurgy, and continuous casting are discussed, showing the range of processes that benefit from greater understanding in this area. This article considers specifically the reaction of liquid ferrous droplets, immersed in molten oxides, involving key alloying components, including phosphorus, aluminum, and carbon. The studies use high-temperature-confocal scanning laser microscopy (HT-CSLM), X-ray computed tomography (XCT), phase-field modeling, and in situ limited angle X-ray imaging. These techniques have seen significant development over recent years, and the combination of these powerful tools reveals the occurrence of spontaneous emulsification driven by chemical reaction (in the case of oxygen/phosphorus/aluminum reactions) and gas-phase formation (in the case of decarburization) both internally and externally to a steel droplet. A key finding is that the interfacial area pertinent for the heterogenous reactions to occur changes considerably (by up to an order of magnitude) depending on the chemical driving force. Additional key findings include the shift between preferential internal and external gas nucleation during decarburization, an inflection point of behavior as to whether or not spontaneous emulsification will occur (within the study discussed, this is between 3 and $4 \mathrm{wt}$ pct $\mathrm{Al}$ ) and the pathway of perturbation growth through which spontaneous emulsification occurs, including the physical maxima a perturbation will grow to before breaking away from the parent droplet.

https://doi.org/10.1007/s11663-020-01880-2

(C) The Author(s) 2020

\section{INTRODUCTION}

PROCESS metallurgy is a highly dynamic field, which is challenging for experimentalists due to the inherent difficulty in containment of molten reactive phases, visualization, and measurement. Many metals melt at high to ultrahigh temperatures, which most measurement apparatuses are unable to perform under, ultimately driving the challenges to dissecting the

STEPHEN SPOONER and ZUSHU LI are with WMG, University of Warwick, Coventry CV4 7AL, UK. Contact email: s.spooner@warwick.ac.uk SEETHARAMAN SRIDHAR is with the Department of Metallurgical and Materials Engineering, Colorado School of Mines, Golden, CO 80401.

Manuscript submitted October 16, 2019.

Article published online July 6, 2020. intricacies of engineered reactive environments for these materials. This article considers processing of liquid steel and novel advancements in understanding the reaction pathways undertaken for key refining reactions, occurring across molten metals and oxides, such as carbon, phosphorus, and sulfur removal, which is required for the formation of highly engineered high-value steel grades. ${ }^{[1-6]}$ It also touches upon unwanted reactions involving aluminum in the steel melt.

Liquid steel processes, such as the blast furnace (BF), basic oxygen furnace (BOF), ladle furnaces (LFs), continuous casters (CCs), and novel ironmaking technologies, operate at a temperature range of $1300{ }^{\circ} \mathrm{C}$ to $1600{ }^{\circ} \mathrm{C}$, in general, and involve a molten oxide (slag) phase in contact with the steel melt. Historically, the refining processes of these complex reactors have been studied on a laboratory scale through postanalysis of interrupted quenching trials between binary or tertiary 
systems of liquid metal, slag, and gas ${ }^{[2,7-15]}$; sampling of a larger reacting vessel ${ }^{[8,16-20]}$; or inferred chemical exchange through more bespoke techniques, such as emissivity or viscosity change, when compared against standards. For reaction rate models, this validation is still required today as only exceedingly expensive techniques, such as those harbored at synchrotron facilities, are able to measure chemistries fast enough at these high temperatures; however, even they can struggle due to the nature and stability of iron and its absorption of the radiation types used for these techniques.

These historical techniques have been key to developing steel processes to what they are today, informing matters such as viscosity control to avoid slopping and foaming, ${ }^{[21-23]}$ basicity to encourage partitioning of impurities to the slag phase, ${ }^{[24-27]}$ and the effect of stirring on mass transport of material to increase reaction rates. ${ }^{[23,28-30]}$ However, the techniques fall when a need for understanding the reaction pathway is desired. The kinetics of the concomitant processes, nucleation, growth, agglomeration, interface breakup, etc., which occur at high temperatures, are crucial for evaluating the structures and chemistries resulting from the industrial reactors.

The present-day steel industry operates within a volatile and frugal global market. In order to stay competitive, economies of scale and flexibility in business and process function are required. To gain thermal efficiencies and procurement power, integrated steel mills have grown and in Europe, for example, tend to operate BFs with annual production volumes of between 800 and $2 \mathrm{M}$ tons of steel per annum and significant numbers of sites run multiple BFs. With these scales, what is seemingly a small saving per ton, such as a 1 pct reduction in raw material prices, an increase in productivity, or reduction in the number of problems such as failed BOF blows due to missed chemistry, can become the difference between a thriving steel mill or a mill closing as it becomes unviable against its global competition.

As such, there is a need for continuous improvement and flexibility within the processes in order to ensure streamlined productivity and ability to respond to cheaper raw material choices. In order to enable this, fundamental understanding of how these processes work and the knock-on effects of the changing conditions throughout a process are required to allow correct control of input parameters. This article will consider three key examples of fundamental reaction phenomena, which are now believed to drive the reaction processes in key steelmaking conditions. The studies use a combined application of advanced characterization techniques including high-temperature-confocal scanning laser microscopy (HT-CSLM), X-ray computed tomography (XCT), and phase field (PF) modeling.

These examples are as follows.

(1) The overwhelming influence of metal droplets in the BOF slag/metal/gas emulsion and the effect of oxygen exchange and phosphorus removal on droplet geometries. This understanding is key to en- abling dynamic converter models for controlling phosphorus partitioning, a limiting factor in the use of cheaper iron ores, and controlling reactions and viscosity of the emulsion zone for preventing overfoaming and slopping of the emulsion.

- A combination of rapid furnace treatment and XCT is used to unveil the physical phenomena undertaken by a reacting droplet in a "clean" iron high FeO slag system.

(2) The control of desired chemistry after alloying during ladle treatment/transport and the initial casting process. Alloying is a major material cost to high-value steel production; as such, the yield and retention of these additions is paramount to ensure the grade will perform downstream as expected while limiting the need for adding expensive raw materials. The fundamental reaction is also relevant for the continuous casting process wherein unwanted reactions between the steel strand and silicate-rich mold slag may occur.

- Iron-aluminum droplets are observed in situ using HT-CSLM, combined with ultrahigh resolution XCT and PF modeling, to understand the pathway of spontaneous emulsification and its limiting factors.

(3) Smelting ironmaking technologies are fast becoming the prominent method expected to be taken up for hot metal reduction with reduced $\mathrm{CO}_{2}$ for environmental benefit. These technologies rely on carbon-saturated droplet ejection into the slag phase to ensure high interfacial area/high productivity, for reduction or iron oxide introduction through iron ore addition.

- Due to the need to observe gas generation for this reaction, the experiment uses limited angle XCT for in situ observation of iron-carbon droplets heated inside a small infrared furnace. Through this method, both internal and external gas generation is observed dependant on reactant concentrations.

The main advantages of the authors' studies presented are the advancement in characterization techniques and the clarity of phenomena and driving force they uncover for the processes studied. As such, it is important to consider the benchmark against which these findings are to be compared.

Within the literature, there are many exemplary examples of liquid metal droplet studies, which have allowed the progress of knowledge on the behavior of material under relevant steelmaking conditions. These can be categorized into splashing/capture studies, quenching trials, and early in situ observation methods.

Prominent splashing/capture studies and the resultant theoretical modeling work include those of Subagyo et al., ${ }^{[31]}$ Sabah and Brooks, ${ }^{[32]}$ and He and Standish, ${ }^{[33]}$ where high-temperature experimentation, water modeling, and theoretical understanding were combined to understand the size and nature of metal droplets formed due to gas injection and how these droplets may progress spatially through a slag layer with transient 
conditions of droplet trajectory, physically induced breakup, and chemically induced bloating occurring. The limitations of these works are centered on the replication of steelmaking environments, with either only a single liquid phase being used or the application of low-temperature knowledge such as cold ballistics and reaction kinetics or substitutional mediums. Nevertheless, this body of work generated by the portfolio of collaborating researchers led to groundbreaking knowledge such as that regarding lance impingement effects and the idea of gas-generation-induced droplet bloating, which have been highly used over the last 20 years to improve primary steelmaking process efficiencies.

Quenching methods have been integral to investigating the secondary refining processes in steelmaking. Investigations into the effects of composition on metal/ slag interfacial tensions finding oxygen, sulfur, and phosphorus to be largely responsible for lowering of interfacial tension under equilibrium conditions form the building blocks for present understanding. ${ }^{[34-40]}$ This foundation of interfacial tension studies is combined with notable findings from Riboud and Lucas, ${ }^{[41]}$ Chung and Cramb, ${ }^{[42]}$ Tanaka et al., ${ }^{[43]}$ and Rhamdhani et al. ${ }^{[44-46]}$ to present cases where the effects of a reactive species crossing the phase interface were found to contribute to the lowering of interfacial tension to an extent that allowed droplets to distort and break apart into numerous smaller droplets and the reaction seemingly countering the energetic cost of the resulting larger interfacial area. Rhamdhani et al. ${ }^{[45]}$ took an approach of considering the cumulative energetic effects interfacial reaction could cause and how these would combine to lower interfacial tension to the lowest possible levels while still maintaining coexisting independent phases.

The final group of underpinning work supporting the advancements of this article are the modern in situ observations, which began with Molloseau and Fruehan $^{[47]}$ and were built upon by the collection of researchers working with Chen and Coley ${ }^{[48]}$ and Coley. ${ }^{[49]}$ These researchers used X-ray fluoroscopy and radiography to visualize the movement of metal droplets at high temperature during reaction and found the rate at which droplets emit gaseous reaction product, oscillate in size, and density, ultimately providing proof that droplets may exist for an extended period of time within gas/slag/metal emulsions contributing extensively to the overall effective interfacial reaction area that exists within steelmaking processes.

\section{BEHAVIOR OF METAL DROPLETS IN THE BOF}

Approximately 70 pct of the steel produced worldwide is through the integrated $\mathrm{BF}-\mathrm{BOF}$ route ${ }^{[50]}$ making the BOF, which seems like a simple converter furnace on the surface, a critical technology to the existence of steel in its plethora of uses today. The understanding of the BOF has undergone continual development, and with regard to the pathway of refining, there are two key contrasting models in existence: (1) The understanding that the exceedingly high temperatures in the "hot zone" (the impingements area of the oxygen gas jet) cause reactions to occur in this area at such a high rate the contribution of this zone is vastly significant; ${ }^{[21,51-53]}(2)$ the gas/slag/metal emulsion is the most significant contributor to the reaction processes in the BOF due the cumulative vast interfacial area between slag and metal, which is generated and held here due to the high number of droplets and overall volume of the emulsion. ${ }^{[52,54-61]}$

The hot-zone-controlled model works on the principle of elevated temperatures in the hot zone of the $\mathrm{BOF}$ (the area directly under the nozzle of the oxygen lance). These temperatures are assumed based on the high availability of oxygen exciting the lance and reacting with carbon in the bulk steel bath around the impingement zone to form $\mathrm{CO}$ and $\mathrm{CO}_{2}$ gas products. This exothermic reaction is believed to drive up temperatures and, thus, enable faster reactions of $\mathrm{P}, \mathrm{Si}, \mathrm{Mn}, \mathrm{S}$, etc., the secondary requirements of the BOF after decarburization. The limitations of this assumption are the transport of reacting/product species through the slag phase and the overall "small" area of interaction that the hot zone accounts for.

The droplet-emulsion-controlled model is built on the premise of the cumulatively larger interfacial area generated and sustained in the emulsion zone between liquid metal droplets and slag, when compared to the hot zone and quiescent bulk bath surface areas. In addition, the droplets are moving throughout the slag regenerating reactants at the interface, maintaining the maximum chemical potential driving reactions forward. Previous work by the authors used a unique set of data from a pilot scale BOF and investigated the amount, residence time, and circulation rates of the emulsion metal, concluding from a simple carbon mass balance that approximately 60 pet of decarburization could be accounted for from metal packets in the emulsion zone. ${ }^{[62]}$ This value is also supported by other literature sources with calculation methods including full-scale BOF sampling and fundamentally driven dynamic models. ${ }^{[63,64]}$

Dynamic converter models are currently showing a strong potential to offer the level of understanding and parameter balancing required to fine-tune the gains in performance previously mentioned, which are required to ensure the viability of a steelmaking process long term. A plethora of information is required to construct these models, including droplet generation, heat/mass balancing, reaction potentials, and metal/slag interfacial area. This last factor of interfacial area through emulsion droplet control has driven recent developments in the process understanding. Initial calculation of expected droplet trajectories showed less than a second of existence in the emulsion. ${ }^{[65]}$ However, development of theories around gas generation due to decarburization causing droplet halos or bloating has been key to understanding the relative density of the metal being reduced, and the droplets not only float in the slag layer for an extended period ${ }^{[31,47,51,54,66-69]}$ (of up to around 2 minutes depending on size and reaction potential) but also grow slightly to increase interfacial area even more. In addition, the present authors have explored droplet 

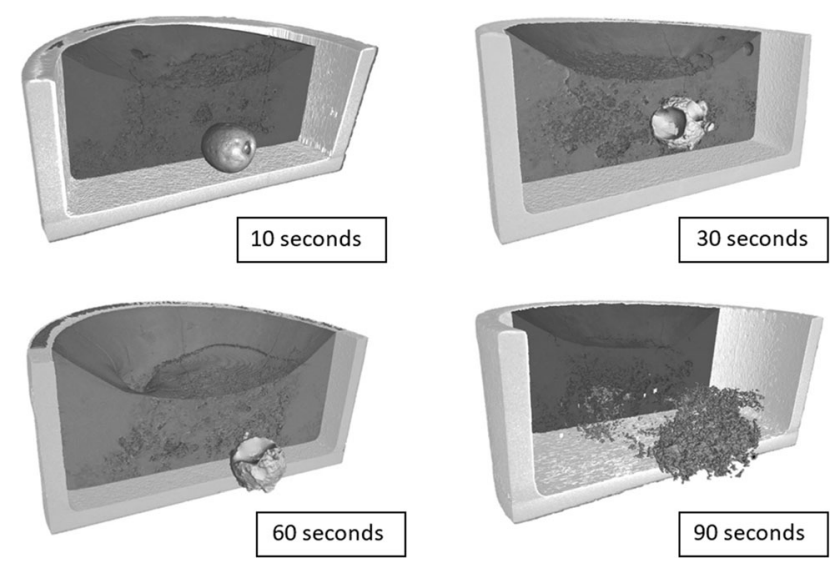

Fig. 1-3-D reconstructions of the Fe-FeO samples held for (a) $10 \mathrm{~s}$, (b) $30 \mathrm{~s},(c) 60 \mathrm{~s}$, and (d) $90 \mathrm{~s}$. The crucible and slag phase have been "peeled" back in order to reveal the metal droplet and its changing morphology.

reactions under non-gas-producing conditions and have observed the phenomenon of spontaneous
emulsification. ${ }^{[0-74]}$

Small pucks (approximately $17 \mathrm{mg}$ ) of electrically pure iron with $<34 \mathrm{ppm}$ oxygen were loaded in the center of 8 -mm-OD $\mathrm{MgO}$ crucibles surrounded by a slag with composition similar to that seen at the end of $\mathrm{BOF}$ processing. The most notable reactant in the slag phase was the 36 pct $\mathrm{FeO}$ content. This high oxygen potential in the slag presents a strong driving force for oxygen transport into the metal phase through reduction of iron via Eq. [1]. The crucibles were rapidly heated to $1600{ }^{\circ} \mathrm{C}$ using an IR gold-coated furnace, held at reaction temperature for a given period of time, and subsequently quenched using helium gas. Due to the heating method, the small size of the sample, and the cold environment within the furnace, these samples are reliably frozen in a state similar to those at high temperatures. The application of XCT as a nondestructive technique allows the imaging of the droplets without sectioning or milling, methods which would destroy the complex geometries the droplets uptake, as seen in Figure 1:[71]

$$
\underline{\mathrm{Fe}^{2+}}+\underline{\mathrm{O}^{2-}} \rightarrow(\mathrm{Fe})+(\mathrm{O})
$$

where species underlined are in the slag phase and those in parentheses are in the metal phase (this will be the standard notation throughout the manuscript).

Figure $2 .{ }^{[71]}$ shows the interfacial area change between the metal and slag as this transient process occurs through the use of three-dimensional (3-D) visualization and quantification software applied to the XCT images. The interfacial area is seen to increase by an order of magnitude.

In addition to the base system, an additional system, which introduces phosphorus as an impurity that will react with $\mathrm{FeO}$, as seen in Eq. [2], was conducted. ${ }^{[70]}$ The $\mathrm{XCT}$ reconstruction of this set of samples is shown in Figure 3 and the interfacial area measurements are included in Figure 2. In Figure 3, we can see the initial $t$ $=0$ second sample flow through a melting profile to

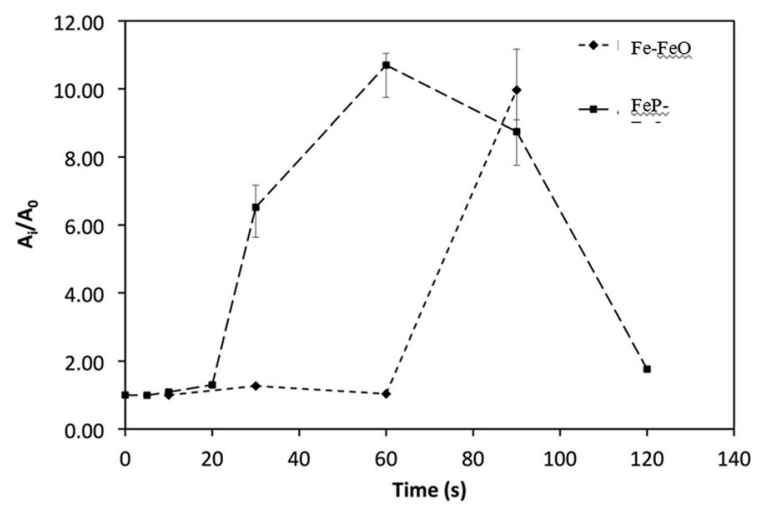

(a)

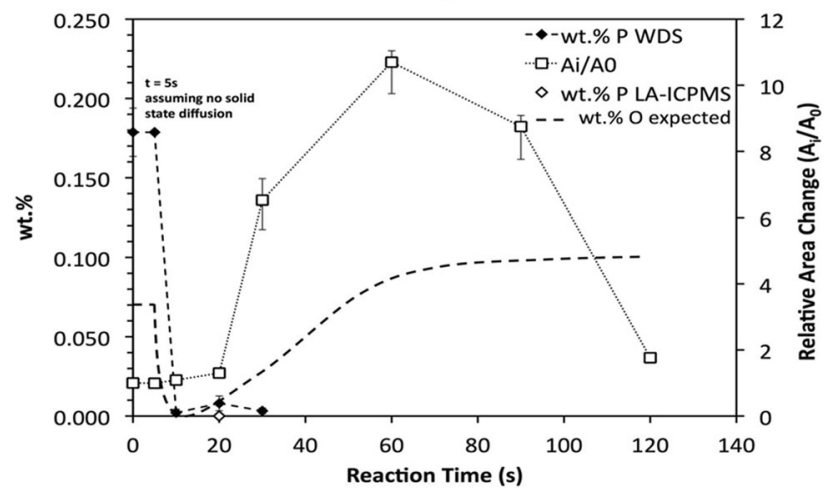

(b)

Fig. 2-(a) Relative surface area change of the metal droplet with time for both the $\mathrm{Fe}-\mathrm{FeO}$ and $\mathrm{FeP}-\mathrm{FeO}$ systems. (b) The relative interfacial area of the FeP-FeO system samples coupled with measured phosphorus and oxygen content from samples early in the process and a calculated oxygen equilibrium value for after reliable measurements were not possible on the emulsified droplets. ${ }^{[71]}$

form a sphere ( $t=20$ seconds) and, subsequently, seem to explode into a cloud of smaller droplets $(t=30$ to 90 seconds), which after a period of time, coalesce back into a single droplet. ${ }^{[70]}$

$$
(2 \mathrm{P})+\underline{5 \mathrm{FeO}} \rightarrow \underline{\mathrm{P}_{2} \mathrm{O}_{5}}+(5 \mathrm{Fe})
$$

Both systems were sectioned and the chemical composition measured using techniques including LECO* ultimate chemical analysis tools and wavelength-dis-

$*^{*}$ LECO is a trademark of LECO Corporation, St. Joseph, MI

persive spectroscopy/scanning electron microscopy. These composition changes for phosphorus and oxygen (including thermodynamic predictions for oxygen) are superimposed on the transient interfacial area profiles within Figure 2. ${ }^{[71]}$ From the composition measurements, we can see phosphorus is removed from the metal phase before spontaneous emulsification occurs; however, the fluctuation of the oxygen profile across the system matches up well with the initial increase in surface area. It is believed that the exchange of oxygen across the interface causes a drop in interfacial tension and allows the droplet to break apart in order to 


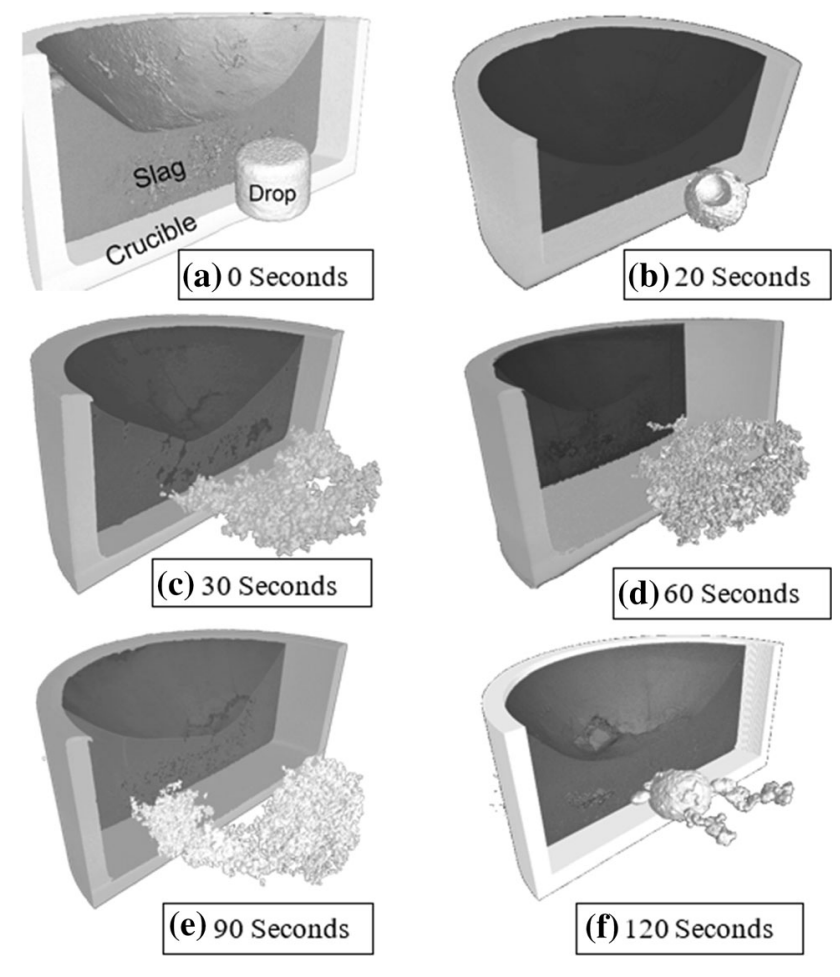

Fig. 3-3-D reconstructions of the $\mathrm{FeP}-\mathrm{FeO}$ system where samples have been held for $(a) 0 \mathrm{~s},(b) 20 \mathrm{~s},(c) 30 \mathrm{~s},(d) 60 \mathrm{~s}$, (e) $90 \mathrm{~s}$, and $(f)$ $120 \mathrm{~s}$. The crucible and slag layer have been graphically peeled back to reveal the metallic droplets within the sample.

overcome the mass transfer control of the oxygen in the slag phase and to speed up the system's progress toward chemical equilibrium. Once equilibrium is reached, this rapid exchange of material no longer exists, the interfacial tension increases again, and the droplets merge back together in order to minimize the interfacial area. The system containing phosphorus began emulsification slightly quicker than the $\mathrm{Fe}-\mathrm{FeO}$ system; it is believed the phosphors contributed to the buildup and speedup/exaggeration of an early step in the process as opposed to the main emulsification phenomenon.

Droplets in the BOF emulsion are subject to similar and greater chemical potentials across their interface. In the turbulent emulsion, where gas layers may be disrupted, this breakup of the droplets into sizes, which will be subject to multidirectional flows in the emulsion, is expected to be an additional contributing factor to the residence time of the emulsion metal, increasing the cumulative interfacial area and adding to the level at which the emulsion zone is likely to control the overall BOFs' refining performance. The level at which this phenomenon occurs will be key to converter understanding and the model being driven by the correct fundamental reaction phenomena providing reliable predictive modeling.

\section{PROCESS AND MELT CHEMISTRY STABILITY IN NEXT-GENERATION HIGHLY ALLOYED STEELS}

Steel has been an ever-evolving material, improving in strength, hardness, and wear resistance as applications desired. One of the big challenges of the twenty-first century is environmental control, which is yet another area whose issues steel is expected to evolve into solving. In application to the automotive industry, two key challenges are relevant: electrification and light weighting. With regard to electrification, the demand of volume and performance of electrical steel for motors is an area of rapid investigation; for light weighting, an option being considered is low-density steels. These applications require heavily alloyed steels with silicon and aluminum, respectively. Both silicon and aluminum are easily oxidized in the conditions seen within LFs when they are added or the material is transported to the caster. The reaction described in Eq. [3] would be undesirable since it leads to loss of aluminum and substantial changes in the slag structure, including crystallization. The latter, especially, would have serious consequences on process control and product quality in the $\mathrm{CC}$. Oxygen is inherently hard to control during these processes due to vessel swapping, and with regard to aluminum, a reaction with silicon oxide (present in many LF and mold slags) is thermodynamically favorable (Eq. [2]):

$$
(4 \mathrm{Al})+\underline{3 \mathrm{SiO}_{2}} \rightarrow \underline{2 \mathrm{Al}_{2} \mathrm{O}_{3}}+(3 \mathrm{Si})
$$

During stirring and activities such as tapping, droplets of liquid alloy are entrained in the slag phases. In order to investigate the stability of heavily $\mathrm{Al}$ alloyed steels, cylinders of $1,2,3,4,5$, and 8 pct Al were loaded into sapphire crucibles surrounded by a slag containing 23.11 pct $\mathrm{SiO}_{2}{ }^{[72]}$ These crucibles were heated in the HT-CSLM and droplets were observed in situ using the ultraviolet imaging laser. Due to there being no transition metal oxides in the slag, the metal droplets were visible subsurface. More detail on the experimental method is given in the initial article reporting the findings. ${ }^{[72]}$ Time-stamped sequences of the 3,4 , and 5 pct videos are shown in Figures 4, 5, and 6, respectively.

From these figures, the parents' droplets are initially visible and a level of perturbation growing into the focal plane can be seen surrounding the droplets; in the case of 4 pct (partially) and 5 pct Al droplets, they can been seen to break apart into a cloud of droplets, before coming back together as a single droplet again. Thus, spontaneous emulsification due to a reaction across the interface is observed again. For 3, 2, and 1 pct Al, a reducing level of perturbation was observed in adherence to the starting $\mathrm{Al}$ content before the droplet became a quiescent sphere again.

The HT-CSLM is able to raster in the $z$-plane and images collected were converted to a two-point gray scale (metal white, slag black) through image partitioning using Matlab (a software product of MATHWORKS). The surface area between these two phases was measured at several points in time for each of the six experiments and the relative changes in surface area are 


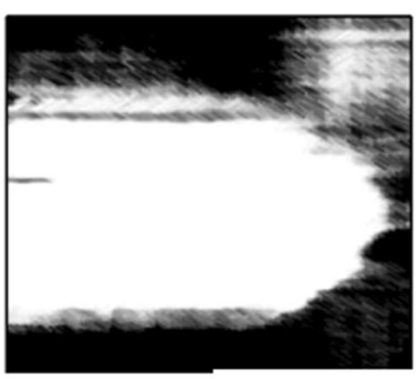

2.1

(a)

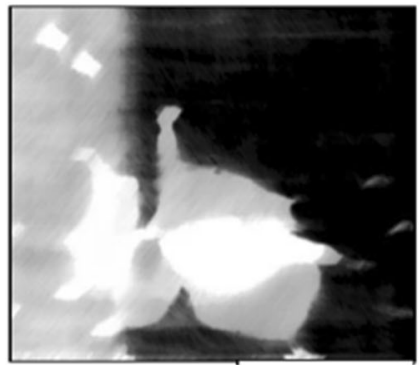

8.1

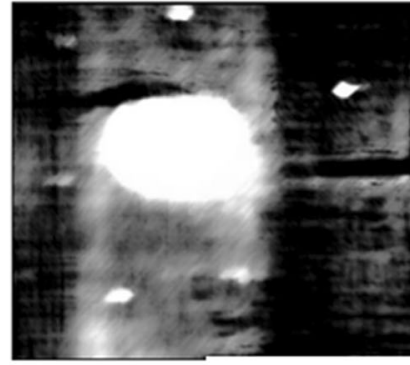

4.1

(b)

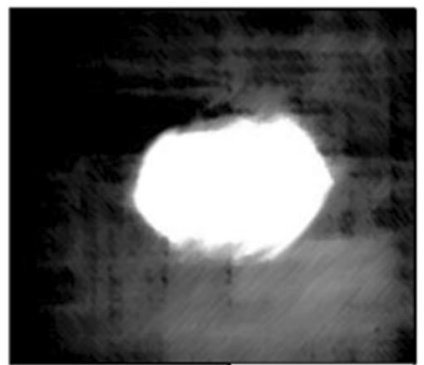

12.1

(e)

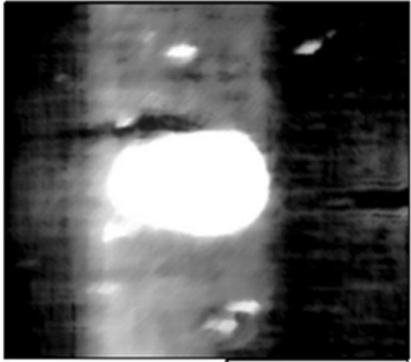

7.1

(c)

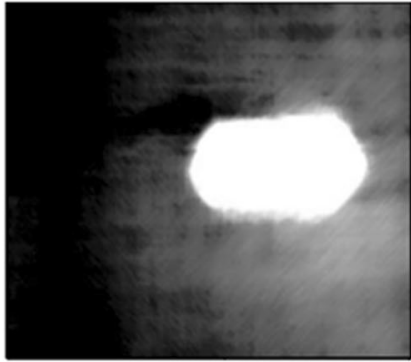

15.1

(f)

Fig. 4-Time-stamped image sequence of the 3 pct aluminum sample. $(a)$ The droplet is seen coming into view, $(b)$ through $(d)$ perturbations begin and grow, and $(e)$ and $(f)$ the droplet forms a quiescent sphere without emulsifying at all. Reprinted from Ref. [72], http://creativecom mons.org/licenses/by/4.0/.

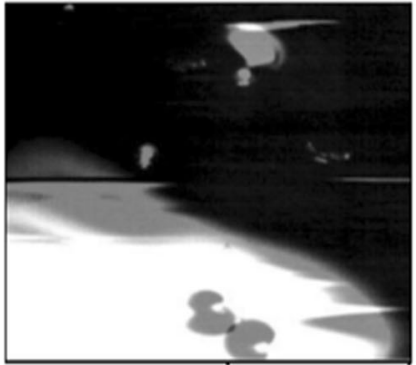

2.1

(a)

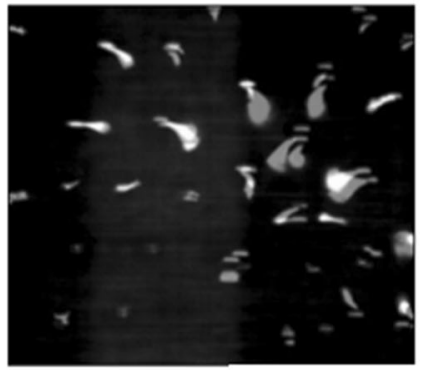

8.1

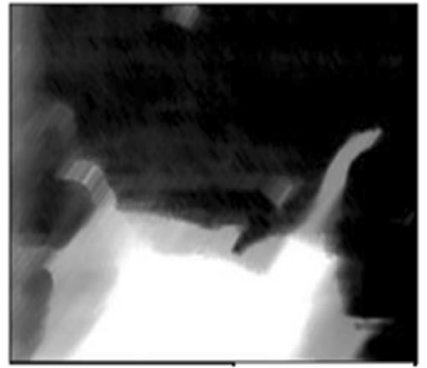

4.1

(b)

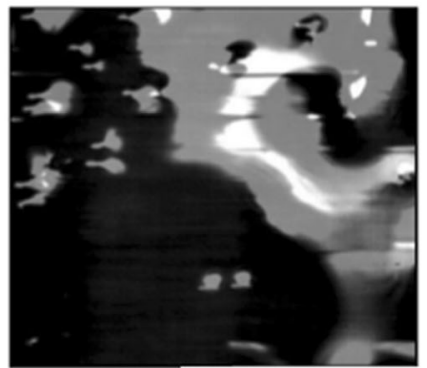

12.1 seconds

(e)

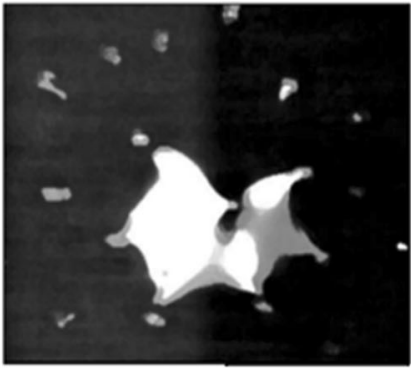

7.1

(c)

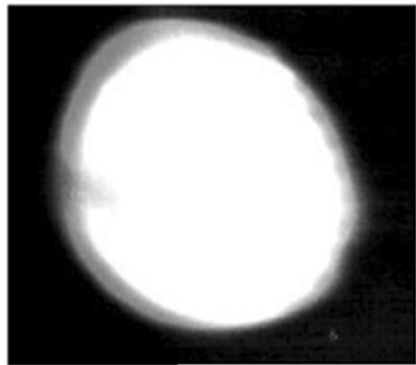

15.1 seconds

(f)

Fig. 5-Time-stamped image sequence of the 4 pct aluminum sample. (a) The droplet can be seen to come into view, (b) through (d) perturbations begin and grow, $(e)$ a clouding of the metal droplet occurs, and $(f)$ the droplet coalesces back to a quiescent sphere. The times of the images after reaching molten state are given to the nearest 0.1 of a second. Reprinted from Ref. [72], http://creativecommons.org/licenses/by/ $4.0 \%$ 


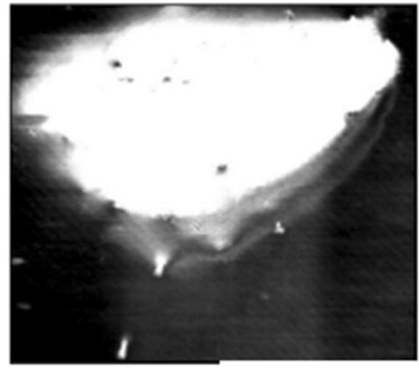

2.1

(a)

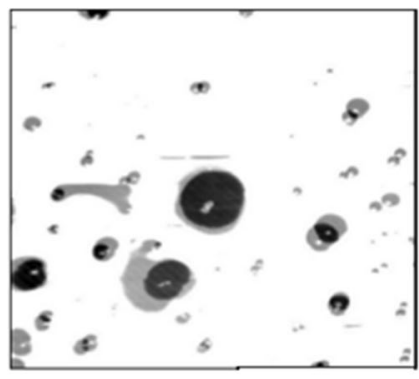

8.1

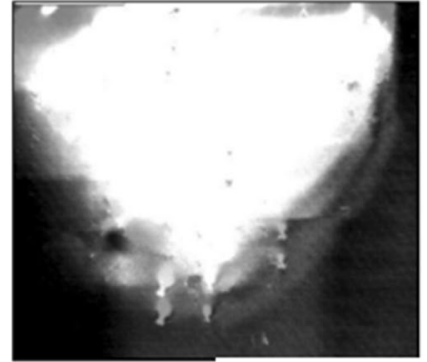

4.1

(b)

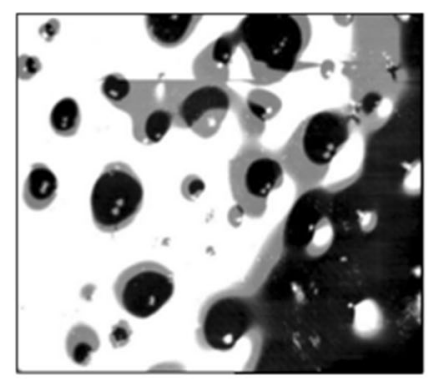

12.1

(e)

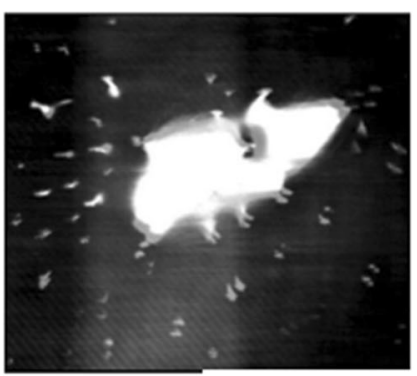

7.1

(c)

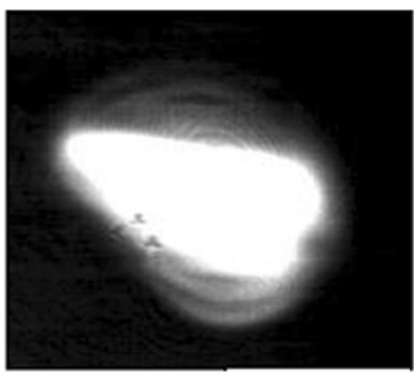

15.1

(f)

Fig. 6- Series of time-stamped images showing the progression of the 5 pct aluminum sample. The droplet can be seen to $(a)$ through $(c)$ have rising levels of perturbation, $(d)$ and $(e)$ cloud into an emulsified dispersion, and $(f)$ coalesce into a quiescent sphere. All times are given to the nearest 0.1 of a second. Reprinted from Ref. [72], http://creativecommons.org/licenses/by/4.0/.

given in Figure $7 .{ }^{[72]}$ From this, it is easily observable that there are two main behaviors: 1, 2, and 3 pct had perturbations that grew to begin with but did not emulsify; 4, 5, and 8 pet did emulsify (however, 4 pet did this in a supressed manner and to a much lesser extent) before coalescing to a quiescent droplet within a similar time frame.

This inflection in behavior shows a key change in the energetics of the system, where there is either enough reaction potential to stabilize the much larger interface of the broken up droplet or not, with the assumption that if the droplet breaks apart it will occur to a given level most probably driven by factors such as density, viscosity, or the starting droplet size. These controlling factors would be an interesting area of further study.

In order to investigate the inflection, a Gibbs free energy calculation for each system reacting to equilibrium was conducted. These total energy gains are plotted in Figure 8 alongside a global interfacial area energy cost of an emulsifying sample with a given interfacial energy of $1500 \mathrm{mN}^{m-1} \cdot{ }^{[75]}$ From Figure 8, there is a clear demonstration that 1,2 , and 3 pct Al samples do not reach the energy cost of emulsification; thus, there is not enough of a driving force for the phenomenon to occur. Whereas 4, 5, and 8 are above this limit and, thus, the droplet is able to break apart to increase the reaction kinetics, 4 pct is only just above the required energy and given variations in experimental performance are the expected reason for the delayed/suppressed level of emulsification observed.

Given the unique ability to observe perturbation of the metal droplets and the fact emulsifying droplets were seen to begin with perturbation, these grew in size and number and finally the droplet clouded, and the physical pathway of the phenomena occurring is believed to be discovered. A reaction across an interface lowers interfacial tension by offering preferred heterogeneous phase interaction. As reactants are depleted around the droplet, a diffusion boundary is created. Natural random perturbation occurs, which impinges into or even across this diffusion boundary, allowing the tip of the perturbation to react faster and, thus, lowering its interfacial tension, which subsequently allows the perturbation to grow. At a given distance, the "friction" of material flowing down the perturbation to allow growth restricts flow more than the growth rate and the perturbation begins to neck. This necking creates strain and eventually the head of the perturbation will bud and break away when a critical local strain is created; the cumulative effect of many perturbations reaching this state manifests as spontaneous emulsification. A diagram is given in Figure 9.[72] depicting a perturbation that has begun to neck. 


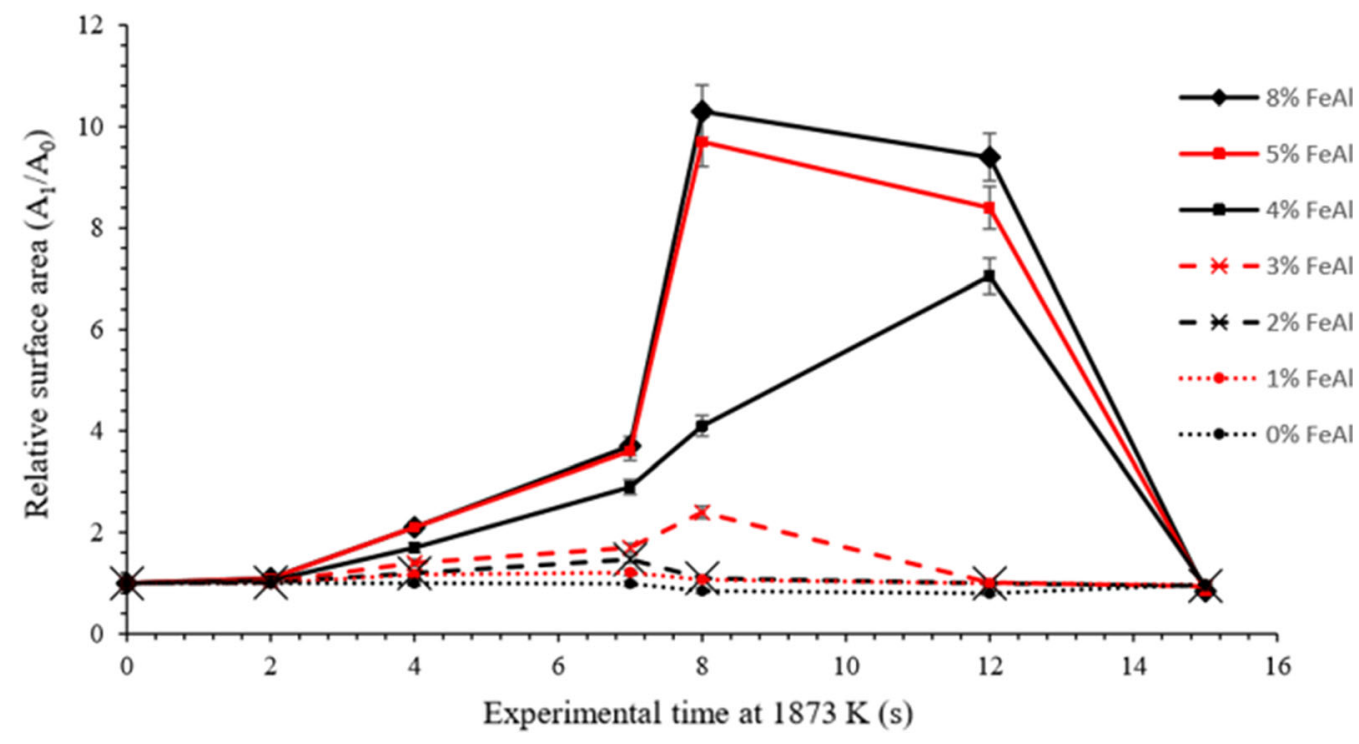

Fig. 7- Changing the relative interfacial area of each of the FeAl droplets with time. 5 and 8 pct aluminum are seen to completely emulsify, 4 pct has a depressed emulsification, and 0 to 3 pct have rising levels of perturbation but no full emulsification/no drastic increase in interfacial area. Reprinted from Ref. [72], http://creativecommons.org/licenses/by/4.0/.

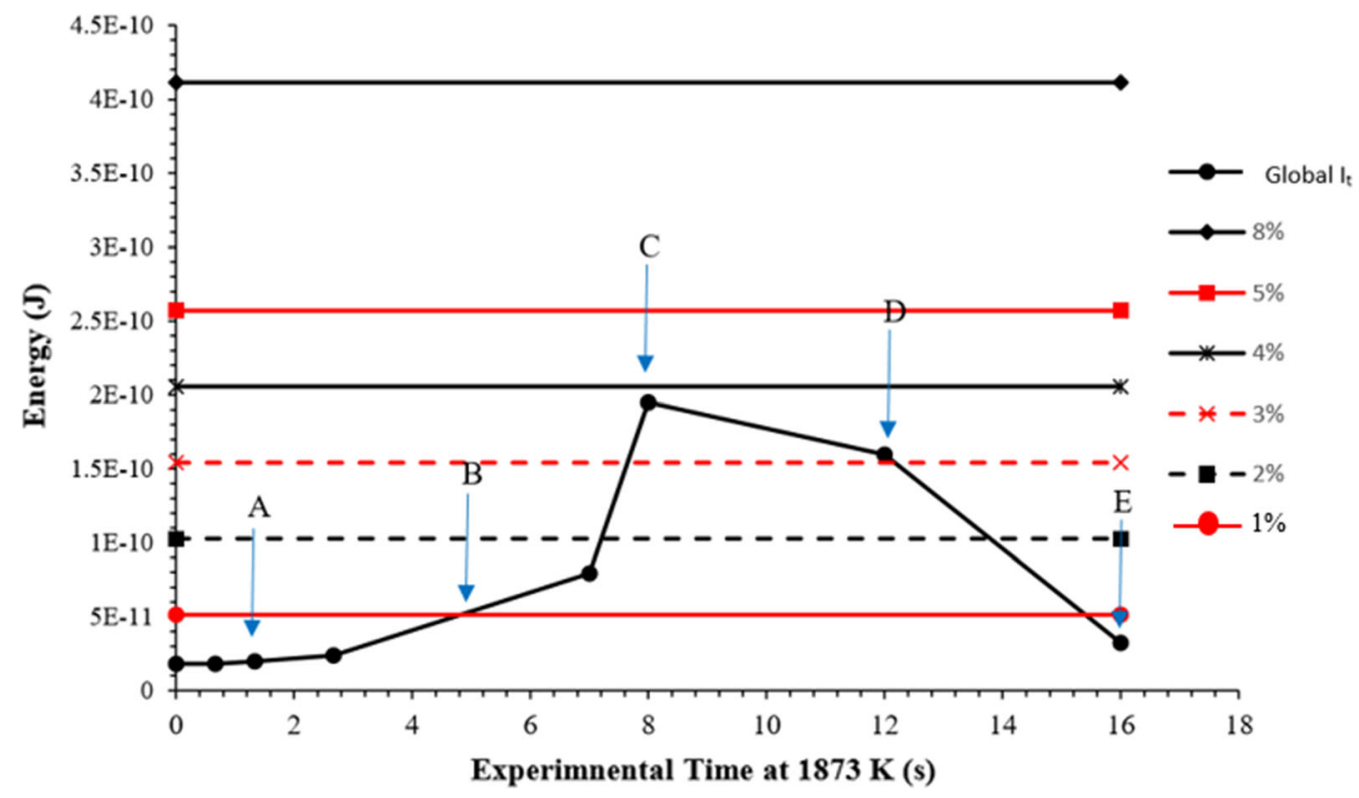

Fig. 8- Gibbs free energy release from the 1, 2, 3, 4, 5, and 8 pct aluminum containing samples reaching equilibrium. Couples with the global interfacial tension cost of increasing the interfacial area of a sample following a matching profile to that measured for the 8 pct sample experimentally. Reprinted from Ref. [72], http://creativecommons.org/licenses/by/4.0/.

Quench samples created using the FeP-FeO system underwent ultrahigh resolution XCT scanning. These droplets can be seen in Figure $10,{ }^{[74]}$ where they have been segmented to allow the quantification of each perturbation's dimensions (length and width) and are color coded with respect to length. It is clearly visible that in the 25-second sample, there are a greater number of perturbations in the larger length range, showing the progression of the phenomena with time. The perturbations were found to have a high population at a 1:1 ratio of length to width, dubbed the "normal" growth regime. $1: 1$ ratio perturbations were seen up to a maximum of $200 \mu \mathrm{m}$, and perturbations deviating from this (where necking is occurring) were found up to a length of 470 $\mu \mathrm{m}$. $^{[74]^{\circ}}$

A phase-field model of the system was created in order to allow prediction of the phenomena's occurrence for more complex and harder to experimentally control systems. The model is detailed in previous works and built on the assumption of driving force stated above 


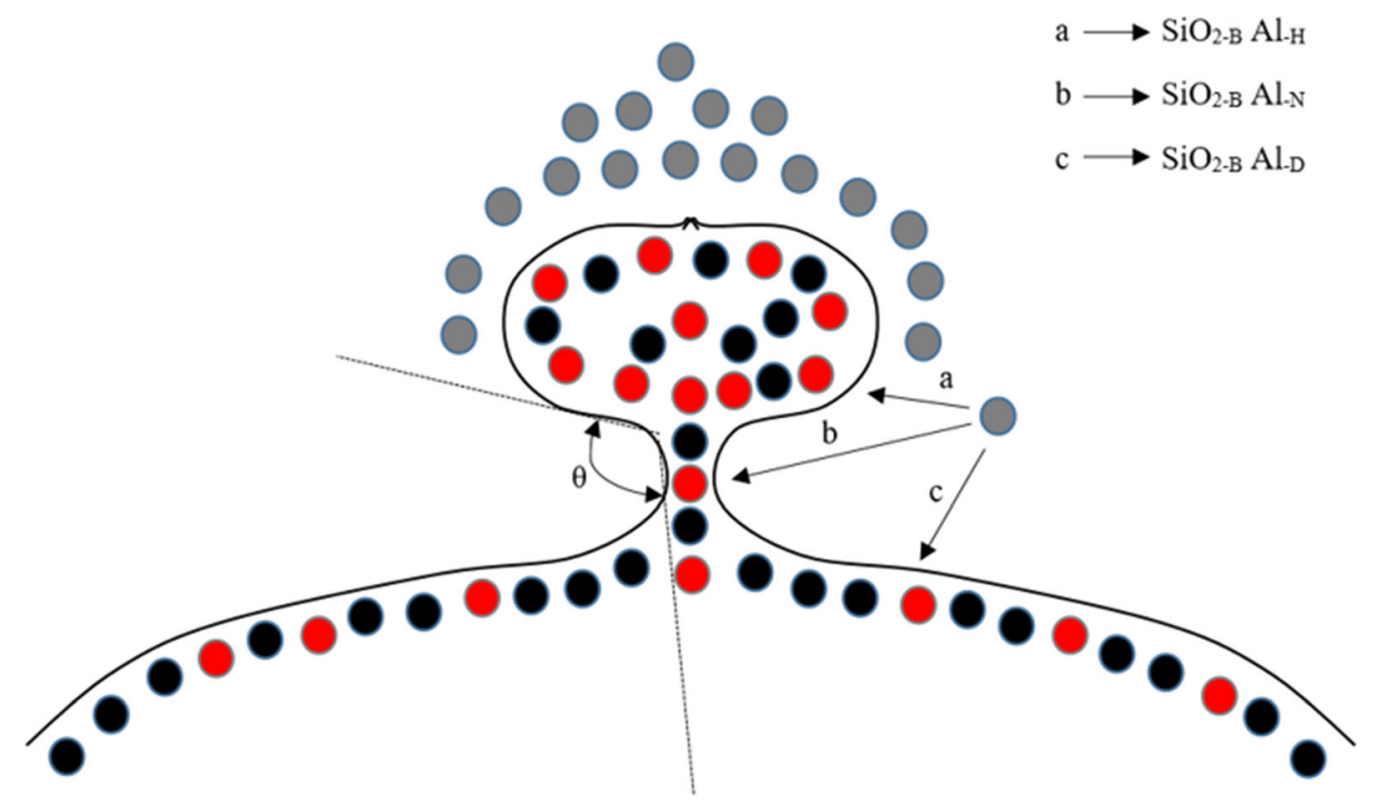

Fig. 9-Cartoon of a perturbation undergoing necking. An example of perturbation growth and necking showing the resultant different diffusion distances due to the perturbation growth of $\mathrm{SiO}_{2}$ bulk particles to perturbation heads $\left(\mathrm{SiO}_{2}-\mathrm{B} \mathrm{Al}-\mathrm{H}\right.$, neck $\left(\mathrm{SiO}_{2}-\mathrm{B} \mathrm{Al}-\mathrm{N}\right)$, and bulk droplet $\left.\left(\mathrm{SiO}_{2}-\mathrm{B} \mathrm{Al}-\mathrm{D}\right)\right)$ is qualitatively depicted. Reprinted from Ref. [72], http://creativecommons.org/licenses/by/4.0/.
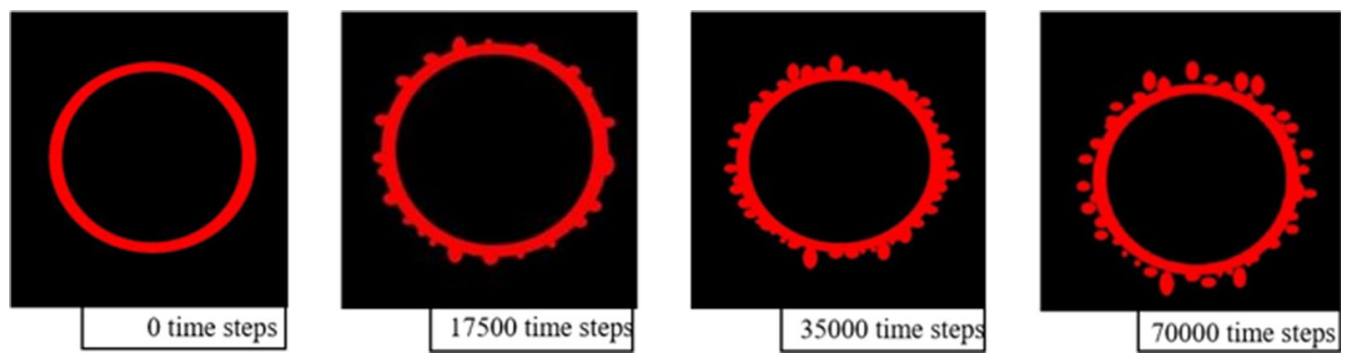

Fig. 10-Sequence of graphical representations from the two-dimensional PF modeling of the Fe-FeO system. The sphere can be seen to perturb; these perturbations grow in size and number, and in the final images, a number of perturbation heads are seen to have broken away to form new desecrate droplets. Reprinted from Ref. [74], http://creativecommons.org/licenses/by/4.0/.
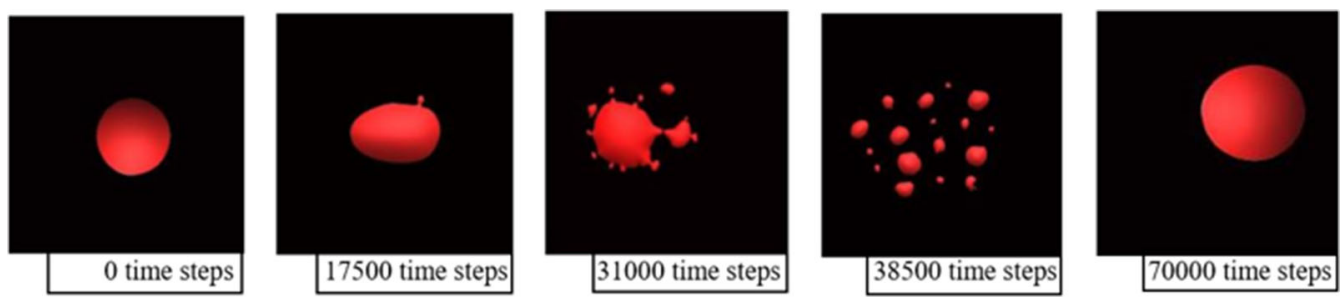

Fig. 11-Sequence of graphical representations from the 3-D PF simulations of the FeAl 8 pct sample. Perturbations are seen to form, grow, and bud with visible "ping back" of the parent droplet, showing the force material could be ejected with a full cloud of smaller droplets and finally a coalesced droplet at the end of the simulation. As this system is so much faster than the Fe-FeO system, the full cycle of droplet behavior is seen over 70,000 time-steps. Reprinted from Ref. [74], http://creativecommons.org/licenses/by/4.0/.

(material exchange across the interface causing a sustained drop in interfacial tension). ${ }^{[74]}$ The model was coupled with in-house visualization software, which was able to create modeled geometries of the $\mathrm{Fe}-\mathrm{FeO}$ system in two dimensions, as shown in Figure $10,{ }^{[74]}$ and the

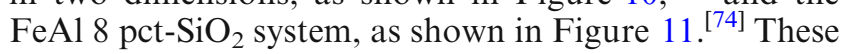
modeled outputs can be rationalized against the experimental work to show a similar time progression of the system; the perturbations observed in the $\mathrm{Fe}-\mathrm{FeO}$ system are of a similar length and width to those measured via ultrahigh resolution XCT. These two factors show the PF model is governed by the correct controlling parameters. Further breakdown of interfacial tensions, strain, concentration gradients, and a 3-D model of the FeAl-SiO ${ }_{2}$ system are reported in depth in the original article. 


\section{GAS PHASE PRODUCTION EFFECTS ON FREE STEEL DROPLETS}

The carbon-oxygen reaction is the prominent consideration for many stages of the steelmaking process from ironmaking, steelmaking, or carbon level control in the final product. For liquid processing, metal droplets again are considered to be the controlling pathway for both reduction of iron oxides in novel smelting ironmaking technologies and for decarburization in the BOF.

Due to the generation of gas phase products $(\mathrm{CO} /$ $\mathrm{CO}_{2}$ ), traditional quench studies are unable to reveal the transient mechanism by which decarburization of steel occurs (the gas will always escape in some way on cooling); as such, this reaction has been a key driver to developing in situ visualization technologies. With the presence of iron oxides in the slag, the slag is no longer optically transparent when molten as in the preceding example; to bypass this, the use of X-ray facilities has been employed.

Two prominent laboratories in the field of pyrometallurgy have produced a series of well-respected journal publications in this immediate area. ${ }^{[4,69,66]}$ They use an experimental setup where a vertical tube furnace is positioned between $\mathrm{X}$-ray radiography equipment. These studies have been invaluable in their findings of gas phase phenomena such as the generation of a "gas halo" and "bloated droplets" during the decarburization reaction. The discovery of these phenomena has been key to understanding fundamentals such as phase interaction conditions and the necessary diffusion of $\mathrm{CO} / \mathrm{CO}_{2}$ as transport species across the gas halo (carrying oxygen to the droplet and carbon away). The bloated droplet, as previously discussed, is key to understanding the ability of metal droplets to maintain residence in the emulsion phase of the BOF, the trapped gas reducing the "average density" of the particle. The studies have shown at which levels of carbon and the time period a slag may maintain its lower density state before it is likely to begin decent back into the bulk bath. ${ }^{[64,77-80]}$

Due to the size of the specimens being studied and the capabilities of the setups, there has been a limitation in the visual output due to the metallic phase scattering $\mathrm{X}$-ray and significant mobility within the samples. To improve the understanding, the present authors have taken an approach to fine-tune these trials to produce clearer images to inform high-accuracy quantitative evaluations of the decarburization for improving understanding and application to fundamentally driven dynamic process models.

The authors present some initial results using a novel limited angle scanning XCT method to generate high-resolution in situ visualization of decarburizing liquid metal droplets. A small IR sessile drop furnace with boron silicate windows for low X-ray interaction was placed inside a Nikon $225 \mathrm{kv}$ XCT scanner. The furnace-heated alumina crucibles contained iron carbon droplets of 4 pct carbon and a slag composition similar to that seen inside a midblow BOF. The main reactivate constitution of the slag was 15 pct $\mathrm{FeO}$. The furnace heated at a rate of $700{ }^{\circ} \mathrm{C} / \mathrm{min}$ to a temperature of 1450
${ }^{\circ} \mathrm{C}$. The experimental temperature was then held while XCT scans captured 10 radiographs per second over a 5 deg radius (equally spaced). These images were reconstructed with a 1-second time resolution to produce 3-D reconstructions of the droplets.

Figure 12 shows a time-step image sequence of the reaction droplet via a horizontal ortho slice through the crucible's reconstruction. The ortho slices are extracted at a level following the movement of the droplet to maintain the view of the droplet over time. In the center of the crucible, there is a dark ring of porosity, which grows and shrinks through the time-steps. This is the meniscus of the slag phase with relation to the droplet's location; a schematic to explain this is given in Figure 13.

The droplet appears to contain more porosity when higher in the crucible and less porosity when lower. A key finding is that the droplet appears to oscillate. The understanding behind this behavior is there is a buildup of gas phase in the droplet, which over time (causing the effective density of the droplet to decrease and the droplet to rise in the crucible), coalesces into a critically sized bubble. This bubble eventually grows to a size where it then generates enough force through flotation and velocity to break the droplet's surface (causing the effective density of the droplet to increase again and the droplet to drop in the crucible). This oscillation of droplet density will provide additional insights into how droplets are expected to behave during large-scale processes, and the balance of gas generation with the possibility of an interface between metal and slag still occurring would allow the phenomenon of spontaneous emulsification to occur.

A second experiment containing iron carbon droplets of 1 pct carbon and 10 pct $\mathrm{FeO}$ slag shows a very different behavior. Figure 14 shows a time-stop image of the droplets created in the same method as those in Figure 12. This time the droplet is seen to stay a similar size throughout the reaction and no internal porosity is detectable via X-ray imaging. It should be noted, due to the limited angle scanning and motion within the sample over the scanning period, there is an uncharacteristically high level of noise within the images compared to the quenched XCT samples shown previously; the authors do not definitively state there is no internal porosity generated.

The droplets are still decarburizing, however, with the lower level of iron oxide in the slag phase and overall lower rate of gas generation with less carbon; there appears to be a preference for gas generation at the metal/slag interface - the generation of a potential gas halo similar to an area in the previously discussed work. The generation/stability of the gas halo will be dependent on the level of motion and vigor of gas generated along with the viscosity of the slag phase to maintain the trapped gas. The gas halo will act as a further inhibitor to decarburization as reaction species are now required to diffuse across the gas boundary layer. This additional inhibition to an already lower level of decarburization due to lower chemical potential gives insights into how the final stages of decarburization should be understood and modeled and why the process may take longer to reach the low desired levels of carbon than expected 

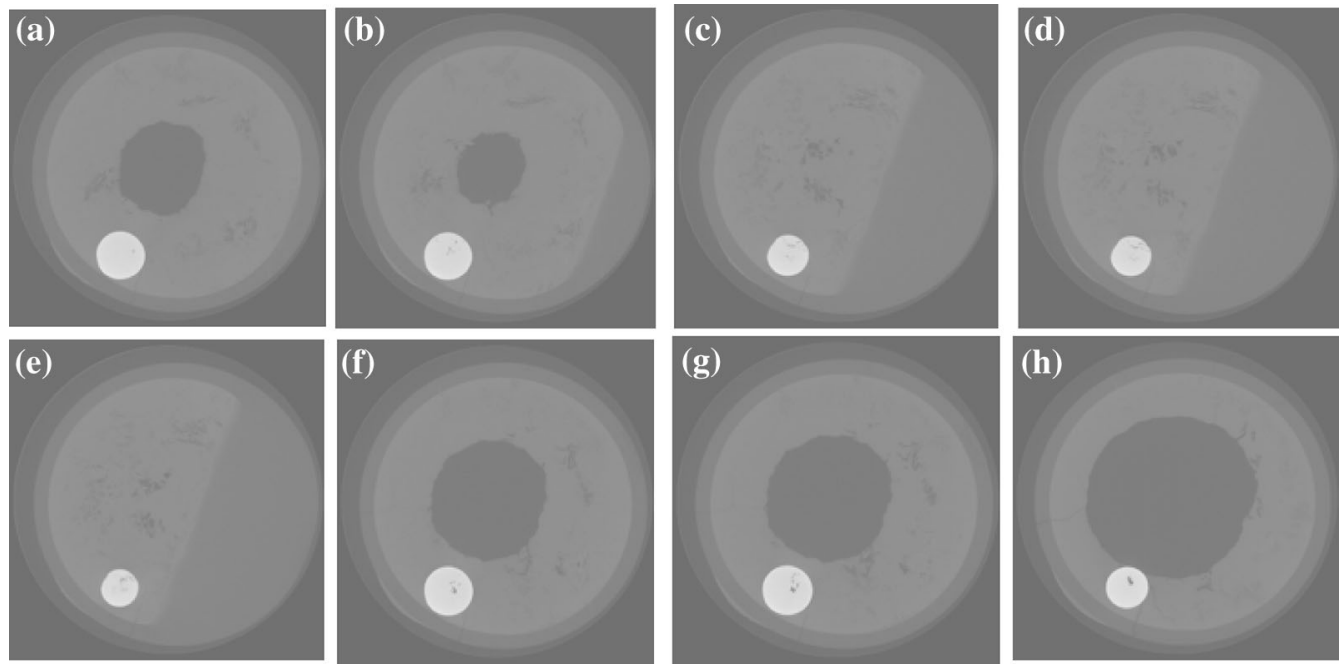

Fig. 12 - Sequence of horizontal ortho slices from the 4 pct carbon droplets in slag containing 25 pct FeO. The first image is (a) $20 \mathrm{~s}$, with each subsequent image following at 3-s intervals: $(b)=23 \mathrm{~s},(c)=26 \mathrm{~s},(d)=29 \mathrm{~s}$, etc.

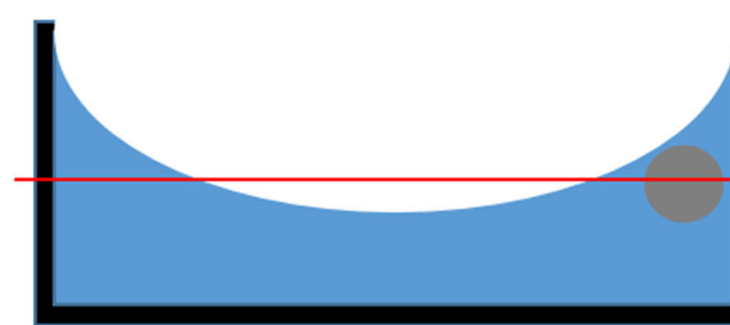

(a)

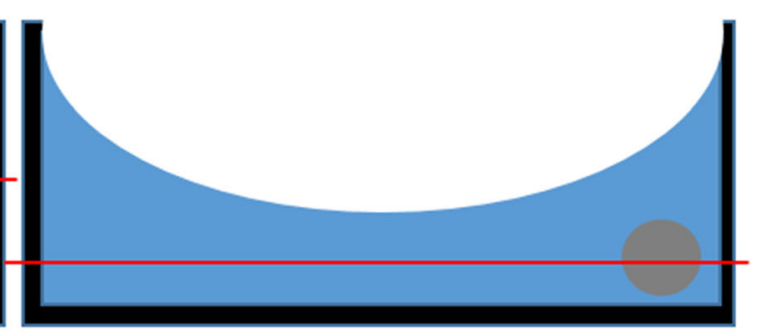

(b)

Fig. 13 - Schematic of the effect of droplet location on the viewing of the meniscus and, thus, the corresponding ability to evaluate the droplet rising and falling in the crucible as it bloats and shrinks due to gas generation and release. The crucible is black, slag blue, and metal droplet gray. (a) The view section cuts through the meniscus and, thus, a black area would be seen in the center of the ortho slice (red line). (b) This does not occur and mostly gray slag will be visible in the ortho slice.

from purely liquid phase kinetics model BOS processes typically run from empirically learned end-point prediction models. Understanding this end part of the blow not only allows improved prediction models but may enable fundamentally driven process models for next-generation steelmaking.

The droplets used in this study are significantly smaller than those used in the bodies of work previously discussed around droplet gas generation. New findings will offer complementary enforcement both in higher resolution of gas phase phenomena and the effect of surface area/volume ratio on the balance between reaction phenomena. Droplets within the BOF, for example, have been reported on the micron to millimeter scale, and the new findings will show if there are key differences between how this range of generated droplets is likely to behave during the refining process.

The authors intend to publish further results and discussion on the range of testing conducted via this method in the future and the relationship between gas droplet phenomena and spontaneous emulsification.

\section{MULTIPLE PHYSICAL PHENOMENA IN COMPLEX REACTION SYSTEMS}

A range of droplet geometries and physical phenomena are discussed throughout this article, which on the surface appears to show contrasting documentation of "what should happen" while these iron-based droplets are reacting with metallurgical slags. Thus, it is important to discuss the findings in direct relation to the environment metal droplets are subject to within liquid-refining processes.

Droplets of steel are ejected from liquid metal baths by gas streams traveling at 1500 to $3000 \mathrm{~km} / \mathrm{h}$; this causes movement and sheer force on the droplets, which cannot be generated and visualized by the presented methods in this article or other laboratory works. As such, the generation of an idealistic gas halo, the formation of perfect bloated droplets, or droplets purely breaking apart due to chemically driven spontaneous emulsification is unlikely. However, this does not diminish the aims of these works. 


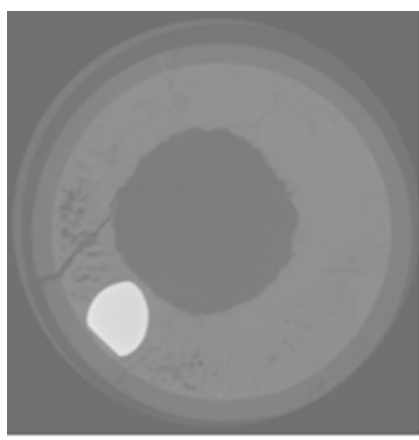

0 seconds

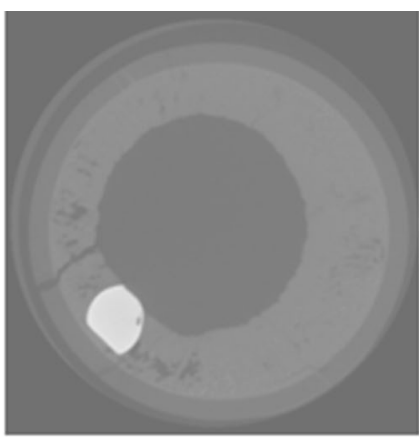

3 seconds

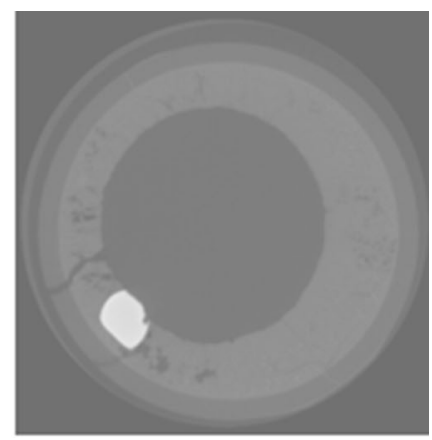

6 seconds

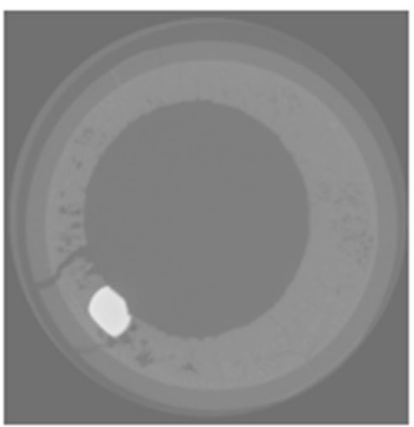

9 seconds

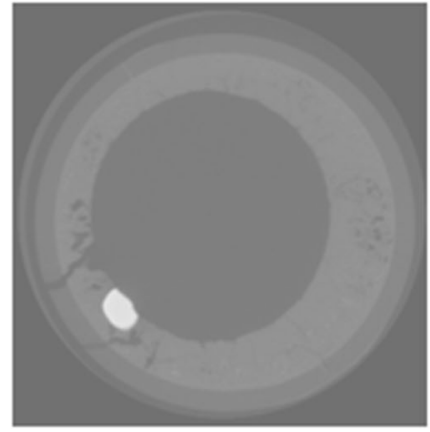

15 seconds

Fig. 14-Ortho slices of the 1 pet carbon droplets in slag containing 10 pct FeO. The droplet is seen to stay a similar size, with no detectable level of internal pores within the droplet. Pores within the slag phase close to the droplet show a reaction is still occurring and the smooth nature of the surface shows something is inhibiting perturbation growth. Thus, a gas halo is expected to be present.

Both mathematical and physical modeling approaches have been undertaken to investigate the generation of droplets $^{[59,81-85]}$ and the sizes of droplets found within reactors, such as the $\mathrm{BOF},{ }^{[52,79,86-88]}$ which have shown these physical forces cannot be the only factor influencing droplet size and geometries. As such, the plethora of research being conducted on droplet reaction kinetics and the observed physical phenomena $^{[11,44,45,47,48,54,73,76,89-97]}$ are key to understanding the fundamental pathway these systems react by and why there is preference against what is mathematically understood. Improved methods of measurement and sampling within converters will be required to completely answer these questions, but in the meantime, studies on more complex alloyed systems and physical parameters, such as temperature, droplet size, and phase viscosities, will be needed to understand the boundaries at which these phenomena occur.

\section{CONCLUSIONS}

The article presents a summary of recent advancements in transient liquid droplet reaction phenomena conducted over the last 5 years. A discussion is given on the need for fundamental understanding to drive improvements in productivity, consistency, and enabling next-generation steel manufacturing.
The effect of oxygen exchange across the slag/metal interface is shown to drive the dramatic phenomena of spontaneous emulsification, where the interfacial area can increase by an order of magnitude. A likely drive to this under steelmaking conditions is the high oxygen potential that can be generated in the slag phase under certain processing conditions.

The stability of highly alloyed steels is shown to be a potential issue for future exotic steel grades, where expensive alloying elements may be lost to slag phases at unexpected rates driven by high chemical potential causing spontaneous emulsification. Due to the phenomena, the loss of aluminum to equilibrium levels can be conducted over similar time periods for 4 to 8 pct aluminum, meaning extra additions may not be a way to overcome this issue. Because of this, there is a need to develop new steel grades in conjunction with materials they are likely to come in contact with to reduce development costs and times for new products.

The phenomena of spontaneous emulsification have been examined both in situ and through quenched samples to unlock the development of perturbation growth over the early stages of the process. Perturbations have been shown to grow, neck, and then bud at a critical distance determined by the diffusion rates and physical properties of the emulsifying phase. Through cross-physical validation, a phase-field model has been developed that has been shown to predict the 
spontaneous emulsification phenomena, showing agreement with the theory of driving force for the droplet breaking apart.

Use of in situ XCT has shown evidence of both droplet bloating and gas haloing and specific examples of when one pathway of gas generation (subsurface/surface) is preferential to the other. These findings show complementary discovery to the body of literature published in this area; however, with the clarity of images, new understanding can be developed.

Overall, the article presents key targeted examples to demonstrate the plethora of undiscovered reaction phenomena that novel techniques and innovative application of existence techniques are able to discover in high levels of detail. The application of the new knowledge able to be extracted by both the present authors and talented researchers globally will be key to maintaining and driving the viable nature of this well-established foundation industry and its future aspirations in competitive product development.

\section{ACKNOWLEDGMENTS}

The authors acknowledge the support for this work by EPSRC through Grant No. EP/N011368/1 and the continued collaboration and funding of Tata Steel Europe.

\section{OPEN ACCESS}

This article is licensed under a Creative Commons Attribution 4.0 International License, which permits use, sharing, adaptation, distribution and reproduction in any medium or format, as long as you give appropriate credit to the original author(s) and the source, provide a link to the Creative Commons licence, and indicate if changes were made. The images or other third party material in this article are included in the article's Creative Commons licence, unless indicated otherwise in a credit line to the material. If material is not included in the article's Creative Commons licence and your intended use is not permitted by statutory regulation or exceeds the permitted use, you will need to obtain permission directly from the copyright holder. To view a copy of this licence, visit http://creativec ommons.org/licenses/by/4.0/.

\section{REFERENCES}

1. X. Hou, Y. Xu, Y. Zhao, and D. Wu: J. Iron Steel Res. Int., 2011, vol. 18, pp. 40-45.

2. M.Y.M. Ahmed: University of Utah, Salt Lake City, UT, 2011.

3. B. Lv, F.C. Zhang, M. Li, R.J. Hou, L.H. Qian, and T.S. Wang: Mater. Sci. Eng. A, 2010, vol. 527, pp. 5648-53.

4. Y. Mandiang and G. Cizeron: Mater. Sci. Eng. A, 1996, vol. 206, pp. 241-48.

5. N. Yoshida, O. Umezawa, and K. Nagai: ISIJ Int., 2004, vol. 44, pp. $547-55$.

6. M.A. Teyeb, S. Spooner, and S. Sridhar: JOM, 2014, vol. 66, p. 1565 .
7. S. Basu, A.K. Lahiri, and S. Seetharaman: Metall. Mater. Trans. B, 2007, vol. 38B, pp. 623-30.

8. S. Basu, A.K. Lahiri, S. Seetharaman, and J. Halder: ISIJ Int., 2007, vol. 47, pp. 766-68.

9. M.A. Tayeb, R. Fruehan, and S. Sridhar: in Int. Symp. on Liquid Metal Processing \& Casting, 2013, pp. 353-58.

10. M.Y. Mohassab-Ahmed, H.Y. Sohn, and H.G. Kim: Ind. Eng. Chem. Res., 2012, vol. 51, pp. 7028-34

11. B. Monaghan, R. Pomfret, and K. Coley: Metall. Mater. Trans. B, 1998, vol. 29B, pp. 29-32.

12. C.P. Manning and R.J. Fruehan: Metall. Mater. Trans. B, 2012, vol. 44B, pp. 37-44.

13. H. Suito and R. Inoue: Trans. Iron Steel Inst. Jpn., 1982, vol. 22, pp. 869-77.

14. H. Suito and R. Inoue: Trans. Iron Steel Inst. Jpn., 1984, vol. 24, pp. $40-46$.

15. S. Basu, A.K. Lahiri, and S. Seetharaman: Metall. Mater. Trans. B, 2008, vol. 39B, pp. 447-56.

16. F. Pahlevani, S. Kitamura, H. Shibata, and N. Maruoka: Steel Res. Int., 2010, vol. 81, pp. 617-22.

17. Z. Tian, B. Li, X. Zhang, and Z. Jiang: J. Iron Steel Res. Int., 2009, vol. 16 , pp. 6-14.

18. M.S. Millman, A. Overbosch, A. Kapilashrami, D. Malmberg, and M. Brämming: Ironmak. Steelmak., 2011, vol. 38, pp. 499-509.

19. M.A. Tayeb: Carnegie Mellon University, Pittsburgh, PA, 2015.

20. P.J. Kreijger and R. Boom: Can. Metall. Q., 1982, vol. 21, pp. 33945.

21. B. Deo, A. Overbosch, B. Snoeijer, D. Das, and K. Srinivas: Trans. Ind. Inst. Met., 2013, vol. 66, pp. 543-54.

22. S.-M. Jung and R.J. Fruehan: ISIJ Int., 2000, vol. 40, pp. 348-55.

23. W. Wu, L. Yang, C. Zheng, and L. Liu: J. Iron Steel Res. Int., 2010, vol. 17, pp. 7-13.

24. E. Belhadj, C. Diliberto, and A. Lecomte: Cem. Concr. Compos., 2012, vol. 34, pp. 34-40.

25. K. Ito and N. Sano: Tetsu-To-Hagane/J. Iron Steel Inst. Jpn., 1983, vol. 69.

26. S.-H. Seok, S.-M. Jung, Y.-S. Lee, and D.-J. Min: ISIJ Int., 2007, vol. 47, pp. 1090-96.

27. L.S. Ökvist, G. Zuo, and J. Ma: Slag Symp., Lulea, Sweden, 2000.

28. S. Kitamura, T. Kitamura, K. Shibata, Y. Mizukami, S. Mukawa, and J. Nakagawa: ISIJ Int., 1991, vol. 31, p. 1322.

29. K. Naito, S. Kitamura, and Y. Ogawa: Ironmak. Steelmak., 2002, vol. 29 , pp. 208-13.

30. J.F. White and D. Sichen: Metall. Mater. Trans. B, 2014, vol. 46B, pp. 135-44.

31. Subagyo, G.A. Brooks, and K.S. Coley: Can. Metall. Q., 2005, vol. 44, pp. 119-30.

32. S. Sabah and G. Brooks: Metall. Mater. Trans. B, 2014, vol. 46B, pp. 863-72.

33. Q.L. He and N. Standish: ISIJ Int., 1990, vol. 30, pp. 356-61.

34. J. Ye and Y. Sahai: Mater. Trans., 1996, vol. 37, pp. 175-80.

35. A. Jakobsson, M. Nasu, J. Mangwiru, K.C. Mills, and S. Seetharaman: Philos. Trans. R. Soc. A, 1998, vol. 356, pp. 9951001 .

36. T. Tanaka and S. Hara: Z. Met., 1999, vol. 90, pp. 348-54.

37. H. Sun, K. Nakashima, and K. Mori: ISIJ Int., 2006, vol. 46, pp. $407-12$.

38. K. Ogino, S. Hara, T. Miwa, and S. Kimoto: Tetsu-to-Hagané, 1979, vol. 65, pp. 2012-21.

39. D. Sichen and J.F. White: Adv. Molten Slags, Fluxes, Salts, 2016, pp. 533-45.

40. H. Gaye, L.D. Lucas, M. Olette, and P.V. Riboud: Can. Metall. Q., 1984, vol. 23, pp. 179-91.

41. P.V. Riboud and L.D. Lucas: Can. Metall. Q., 1981, vol. 20, pp. 199-208.

42. Y. Chung and A.W. Cramb: Philos. Trans. R. Soc. A, 1998, vol. 356, pp. 981-93.

43. T. Tanaka, H. Goto, M. Nakamoto, M. Suzuki, and M. Hanao: ISIJ Int., 2016, vol. 56, pp. 944-52.

44. M. Rhamdhani, K. Coley, and G. Brooks: Metall. Mater. Trans. B, 2005, vol. 36B, pp. 591-604.

45. M. Rhamdhani, K. Coley, and G. Brooks: Metall. Mater. Trans. B, 2005, vol. 36B, pp. 219-227.

46. M. Rhamdhani, G. Brooks, and K. Coley: Metall. Mater. Trans. B, 2006, vol. 37B, pp. 1087-91. 
47. C. Molloseau and R. Fruehan: Metall. Mater. Trans. B, 2002, vol. 33B, pp. 335-44.

48. E. Chen and K.S. Coley: Ironmak. Steelmak., 2010, vol. 37, pp. 541-45.

49. K.S. Coley: J. Min. Metall. B, 2013, vol. 49, pp. 191-99.

50. M. Windows, M. Corporation, K. Hori, and A. Sakajiri: Steel Facts, 2018.

51. D. Min and R. Fruehan: Metall. Trans. B, 1992, vol. 23B, pp. 2937.

52. B. Deo, A. Karamcheti, and A. Paul: ISIJ Int., 1996, vol. 36, pp. 658-66.

53. S. Basu, S. Seetharaman, and A.K. Lahiri: Steel Res. Int., 2010 , vol. 81, pp. 932-39.

54. E. Chen: McMaster University, Hamilton, ON, Canada, 2012.

55. K.S. Coley and G. Brown: STIS, Jamshedpur, India, 2013.

56. M. Swinnerton: University of Wollongong, Wollongong, Australia, 2005

57. S. Emea: Ironmak. Steelmak., 2009, pp. 1-17.

58. M.S. Millman, A. Overbosch, A. Kapilashrami, D. Malmberg, and M. Brämming: Ironmak. Steelmak., 2013, vol. 40, pp. 460-69.

59. Q. He: University of Wollongong, Wollongong, Australia, 1991.

60. Q. He and N. Standish: ISIJ Int., 1990, vol. 30, pp. 356-61.

61. A.K. Shukla, B. Deo, S. Millman, B. Snoeijer, A. Overbosch, and A. Kapilashrami: Steel Res. Int., 2010, vol. 81, pp. 940-48.

62. S. Spooner, J.M. Warnett, R. Bhagat, M.A. Williams, and S. Sridhar: ISIJ Int..

63. C. Cicutti, M. Valdez, T. Pérez, R. Donayo, and J. Petroni: Lat. Am. Appl. Res., 2002, vol. 32, pp. 237-40.

64. B.K. Rout, G. Brooks, M.A. Rhamdhani, Z. Li, F.N.H. Schrama, and J. Sun: Metall. Mater. Trans. B, 2018, vol. 49B, pp. 537-57.

65. G. Brooks, Y. Pan, and K. Coley: Metall. Mater. Trans. B., 2005, vol. 36B, pp. 525-35.

66. N. Dogan, G.A. Brooks, and M.A. Rhamdhani: 2011, pp. 1-14.

67. G. Brooks: Yazawa Int. Symp. Metall., 2003, vol. 1, pp. 965-74.

68. T.A. Steinberg, H.D. Beeson, and B.E. Newton: Flam. Sensit. Mater., 2000, pp. 1-17.

69. R.J. Fruehan, D. Goldstein, B. Sarma, S.R. Story, P.C. Glaws, and H.U. Pasewicz: Metall. Mater. Trans. B, 2000, vol. 31B, pp. 891-98.

70. A.N. Assis, J. Warnett, S. Spooner, R.J. Fruehan, M.A. Williams, and S. Sridhar: Metall. Mater. Trans. B, 2014, vol. 45B, pp. 56876.

71. S. Spooner, A.N. Assis, J. Warnett, R. Fruehan, M.A. Williams, and S. Sridhar: Metall. Mater. Trans. B, 2016, vol. 47B, pp. 2123 32.

72. S. Spooner, Z. Li, and S. Sridhar: Sci. Rep. Nat., 2017, vol. 7 (5450), pp. 1-12.

73. S. Spooner, A.N. Assis, J. Warnett, R. Fruehan, M.A. Williams, and S. Sridhar: in CTSSC-EMI Symp. Tokyo, 2015.

74. S. Spooner, A. Rahnama, J.M. Warnett, M.A. Williams, Z. Li, and S. Sridhar: Sci. Rep., 2017, vol. 7, pp. 1-16.
75. Y. Chung and A. Cramb: Metall. Mater. Trans. B, 2000, vol. 31B, pp. 957-71.

76. K. Coley, F. Ji, G. Brooks, M. Rhamdhani, Y. Pan, and B. Subagyo: in Proc. VIII Int. Conf. on Molten Slags, Fluxes and Salts, Santiago Chile, 2009.

77. B.K. Rout, G. Brooks, M. Akbar Rhamdhani, Z. Li, F.N.H. Schrama, and W. van der Knoop: Metall. Mater. Trans. B, 2018, vol. 49B, pp. 537-57.

78. B.K. Rout, G. Brooks, M. Akbar Rhamdhani, Z. Li, F.N.H. Schrama, and W. van der Knoop: Metall. Mater. Trans. B, 2018, vol. 49B, pp. 2191-2208.

79. N. Dogan and G.A. Brooks: ISIJ Int., 2011, vol. 51, pp. 10931101 .

80. N. Dogan, G. Brooks, and M. Rhamdhani: Iron \& Steel, Technol. Conf., Pittsburgh, PA, 2010, pp. 1091-1101.

81. G.A. Brooks, K.S. Coley, and G.A. Irons: ISIJ Int., 2003, vol. 43, pp. 983-89.

82. N. Standish and Q.L. He: ISIJ Int., 1989, vol. 29, pp. 455-61.

83. N. Dogan, G. Brooks, and M.A. Rhamdhani: ISIJ Int., 2009, vol. 49, pp. 24-28.

84. Q.L. He and N. Standish: ISIJ Int., 1990, vol. 30, pp. 305-09.

85. B.K. Rout, G. Brooks, Subagyo, M.A. Rhamdhani, and Z. Li: Metall. Mater. Trans. B, 2016, vol. 47B, pp. 3350-61.

86. I. Vinckier, P. Moldenaers, A.M. Terracciano, and N. Grizzuti: AIChE J., 1998, vol. 44, pp. 951-58.

87. A.F. Yang, A. Karasev, and P.G. Jönsson: ISIJ Int., 2015, vol. 55, pp. $570-77$.

88. I. Hahn and D. Neuschutz: Ironmak. Steelmak., 2013, vol. 29, pp. 219-23.

89. J.B. Lewis and H.R.C. Pratt: Nature, 1953, vol. 171, pp. 1155-56.

90. I. Moore, S. Spooner, A.N. Assis, J. Warnett, Z.li, R. Fruehan, M.A. Williams, and S. Sridhar: Phoenix, AZ, TMS, Warrendale, PA.

91. M. Pomeroy: McMaster University, Hamilton, ON, Canada, 2011.

92. K.S. Coley, E. Chen, and M.D. Pomeroy: Iron Steel Technol., 2014, pp. 289-302.

93. H. Cho, S. Jung, S. Kim, H. Lee, and Y. Kang: 2014, vol. 54, pp. 2559-68.

94. P. Wu, Y. Yang, M. Barati, and A. Mclean: 2015, vol. 55, pp. 717-22.

95. H. Sun: ISIJ Int., 2006, vol. 46, pp. 1560-69.

96. C.P. Wu: University of Toronto, Toronto, ON, Canada, 2015.

97. T. Gare and G.S.F. Hazeldan: Ironmak. Steelmak., 1981, vol. 8, pp. 169-81.

Publisher's Note Springer Nature remains neutral with regard to jurisdictional claims in published maps and institutional affiliations. 